\title{
Horizontal and vertical distribution of air temperature in a vegetation canopy
}

\author{
A.F.G. JACOBS ${ }^{1}$, J.H. VAN BOXEL ${ }^{2} \&$ R.H. SHAW ${ }^{3}$ \\ ' Department of Meteorology, Wageningen Agricultural University, P.O. Box 9101, NL 6700 HB \\ Wageningen, Netherlands, \\ ${ }^{2}$ Department of Physical Geography and Soil Science, University of Amsterdam, Nieuwe Prinsen- \\ gracht 130, NL 1018 VZ Amsterdam, Netherlands, \\ ${ }_{3}^{3}$ Department of Land, Air and Water Resources, University of Davis, California, USA.
}

Received: 17 February 1992; accepted 6 May 1992

\begin{abstract}
Air temperature measurements within a maize row canopy were carried out to investigate the horizontal and vertical variability of the mean air temperature. Attention was given to finding adequate scaling parameters of the within-canopy air temperature profiles under various atmospheric stratification states. It appeared that in a narrow-row crop the horizontal mean air temperature can vary between $0.1{ }^{\circ} \mathrm{C}$ (night time) and $0.35^{\circ} \mathrm{C}$ (daytime) from its spatial mean value. Exceptions can occur around noon under daytime situations when direct irradiation dominates and where the direct beam illuminates the within-row space of the canopy. Then differences to the spatial mean value of $1{ }^{\circ} \mathrm{C}$ or more can be observed. During daytime, the within-canopy temperature profiles scale well with the above-canopy temperature scale, $\mathrm{T}^{*}$, for 'constant' irradiation and wind speed regimes. During calm evenings, however, the relative within-canopy temperature profile scales very well with the within-canopy free convection temperature scale, $\Theta^{*}$. It appeared that the within-row and across-row heat advection is of minor importance within dense row canopy.
\end{abstract}

Keywords: Temperature, temperature deviation, temperature variability, crop canopy

\section{Introduction}

There is an extensive literature on the temperature behaviour just above and within canopy crops. This is understandable since this temperature distribution is directly connected to the transport of heat and water vapour. A special problem just above and within canopy crops is that, too close to the elements of the crop canopy, the flow field, and other surface processes are influenced by individual surface elements. This means, even for a so-called homogeneous surface, that horizontal inhomogeneities automatically will emerge when attention is focussed close to the surface elements.

Until now, only a small number of outdoor experiments close to the surface elements have been executed in which aspects of the vertical and horizontal var- 
iability of the flow characteristics have been measured. For example, Shaw et al. (1974) and Mulhearn \& Finnigan (1978) made observations of turbulence and turbulent transport of momentum and heat above a rough surface rather close to the roughness elements. Stigter et al. (1976) studied the horizontal homogeneity of the temperature and moisture within a maize canopy. Graser et al. (1987) studied temperature patterns within sorghum canopies with different row spacing.

The temerature distribution within a canopy is of importance in for example the rate of drying of dew drops or rain drops. The lower temperature and transfer mechanism the longer discrete patches within the canopy can remain wet and the more infection by fungi can occur (Zhang \& Gillespie, 1990). Also insight into the exchange mechanism and the consequent scaling parameters is of importance in modeling the canopy in for example crop simulation models (Weiss \& Norman, 1987).

It is our general objective here to investigate some of the temperature characteristics within a row canopy in order to help clarify the within-canopy transfer mechanism of momentum and heat. In particular, the spatial mean, time averaged air temperature profile and its standard deviation have been investigated. Moreover, attention has been given to the governing scaling parameters of the within-canopy air temperature profile and its standard deviation.

\section{Theory}

Under a steady state and thermally stratified atmosphere, the temperature profile near the earth's surface in the surface layer $\left(z>d+20 z_{0}\right)$ can be adequately described by the profile (Arya, 1988):

$$
\mathrm{T}(\mathrm{z})-\mathrm{T}\left(\mathrm{d}+\mathrm{z}_{\mathrm{o}}\right)=\left(\mathrm{T}^{*} / \mathrm{k}\right)\left\{\ln \left((\mathrm{z}-\mathrm{d}) / \mathrm{z}_{\mathrm{o}}\right)-\psi((\mathrm{z}-\mathrm{d} / \mathrm{L})\}\right.
$$

where $T(z)$ is the mean air temperature at height $z, d$ is displacement height, $z_{o}$ is roughness length, $T^{*}$ is the scaling temperature defined by $T^{*}=\mathrm{w}^{\prime} \mathrm{T}^{\prime} / \mathrm{u}^{*}, \kappa=0.4$ is Von Karman's constant, L is Obukhov's stability length scale, $\psi$ is a correction function for thermal stratification and $u^{*}$ is the friction velocity.

During daytime the within-canopy processes are dominated by the large eddy exchange mechanism (Finnigan \& Raupach, 1987; Jacobs et al., 1992). Under these conditions it is to be expected that an appropriate within-canopy scaling temperature will be equal to the above-canopy scaling temperature, $T^{*}$. During night time with strong wind conditions, the exchange mechanism is also expected to be dominated by the above-canopy flow regime, and the temperature regime is expected to again scale with $T^{*}$.

At night under low wind speed conditions, however, a decoupling between the above and within-canopy processes develops. Then, within the canopy a free convection state occurs in which free convection cells are generated by the relatively warm canopy floor (Jacobs et al., 1992). Above the top of the vegetation, the air is stabilized by radiative cooling and thus the unstable vegetation layer is capped and thereby decoupled from the above-canopy region.

At night within a canopy, the crop height and the buoyance flux at the floor are the two variables important to this free convection state. Combining these scales yields a 
free convective velocity scale, $\mathrm{w}^{*}$, and temperature scale, $\Theta^{*}$, (Tennekes \& Lumley, 1972):

$$
\begin{aligned}
& \mathrm{w}^{*}=\left[(\mathrm{h} \mathrm{g} / \mathrm{T})\left(\overline{\mathrm{w}^{\prime} \mathrm{T}^{\prime}}\right)_{0}\right]^{1 / 3} \\
& \left.\Theta^{*}=-\left(\overline{\mathrm{w}^{\prime} \mathrm{T}^{\prime}}\right)_{0}\right] / \mathrm{w}^{*}
\end{aligned}
$$

where, $g$ is gravity, $h$ is canopy height and $\left(\overline{\mathrm{w}^{\prime} \mathrm{T}^{\prime}}\right)_{0}$ the kinematic heat flux at the soil surface. An appropriate estimate at nighttime for the kinematic heat flux at the floor is $\overline{\mathrm{w}^{\prime} \mathrm{T}^{\prime}} \sim \mathrm{q}_{\mathrm{s}} /\left(\rho \mathrm{c}_{\mathrm{p}}\right)$, where $\mathrm{q}_{\mathrm{s}}$ is the soil heat flux at the ground and $\left(\rho \mathrm{c}_{\mathrm{p}}\right)$ the volumetric heat capacity of air, since during nighttime most of the soil heat flux at the base of a reasonable dense canopy is transformed into sensible heat (Garrat \& Segal, 1988).

\section{Materials and methods}

In addition to a continuous measurement program in which the fluxes of heat, mass and momentum were estimated above and within a maize crop canopy (Jacobs \& Van Boxel, 1988a), a more detailed turbulence and within-canopy experiment was carried out at the pilotfarm Sinderhoeve $\left(51^{\circ} 59^{\prime} \mathrm{N}, 5^{\circ} 45^{\prime} \mathrm{E}\right)$ during two weeks in July 1986. Only instruments important for this study will be discussed here.

Above the crop, the mean wind profile was measured with cup anemometers at eleven heights above the ground of $1.7,2.2,2.85,3.5,4.25,5.0,6.0,7.0,8.0,9.0$ and $10 \mathrm{~m}$. The cup-type anemometers were home-made; the starting speed is $0.20 \mathrm{~ms}^{-1}$ and the first-order response distance $(66 \%)$ is $0.90 \mathrm{~m}$. The above-canopy wind profiles were used to calculate the two surface characteristics: $d$ and $z_{o}$, and their course during the growing season (Jacobs \& Van Boxel; 1988a,b). The mean temperature and moisture were measured at 2 levels at heights 2.0 and $4.0 \mathrm{~m}$ with home-made aspirated psychrometers. At a height of $4.5 \mathrm{~m}$, a 3-D sonic anemometer (Kaijo Denki, model DAT-310) and an additional fast-response thermometer and a Lyman- $\alpha$ humidiometer were installed. These instruments provide data about the above-crop thermal stratification of the atmosphere.

Within the canopy, at $0.25 \mathrm{D}$ between two rows (where, $\mathrm{D}$ is row distance), the mean temperature profile was estimated with fast-response thermometers (Van Asselt et al., 1991) at heights above the ground: $0.0,0.1,0.2,0.3,0.5,0.7,1.0$ and 1.4 $\mathrm{m}$. The thermometers were based on the thermocouple principle. The accuracy for measuring the mean temperature was better than $0.05^{\circ} \mathrm{C}$ and their first-order time constant was about $0.08 \mathrm{~s}$. To gain insight into the horizontal variability of the wind speed, at two levels, 0.3 and $0.7 \mathrm{~m}$, measurements were made at $0.25 \mathrm{D}, 0.50 \mathrm{D}, 0.75$ $\mathrm{D}$ and $1.00 \mathrm{D}$.

To obtain some insight into horizontal temperature differences on a larger scale than the row distance, additional temperature measurements were made at one height $(0.4 \mathrm{~h})$. Within the same row 2 thermocouples were placed at $2 \mathrm{~m}$ and $5 \mathrm{~m}$ distance. Across the row 1 thermocouple was placed at $5 \mathrm{~m}$ distance. All additional thermocouples were placed within the row at $0.25 \mathrm{D}$.

Moreover, a 1-D sonic anemometer (Kaijo Denki, model PAT-110) plus an additional fast-response thermometer and a Lyman- $\alpha$ humidiometer were installed at a 
height of $0.7 \mathrm{~m}$ inside the canopy to measure the within-canopy transport of heat and water vapour.

The maize crop (Zea Mays L., cv. Vivia) was planted in rows $0.75 \mathrm{~m}$ apart with plants $0.11 \mathrm{~m}$ apart in the row. The rows were oriented NNE-SSW. During the detailed turbulence experiment, the crop was at the end of the vegetative state, and had a height, h, of $1.70 \mathrm{~m}$ and a one-sided plant area index, PAI, of 3.6. The PAI is the sum of the leaf area index, LAI, and the stem area index, SAI. The plant area distribution, a, which is an important parameter in modeling the within-canopy flow, has been plotted in Fig. 1 in schematic and nondimensional form. The plant area distribution is defined as the one-sided plant area (i.e. leaves and stems) per unit volume air.

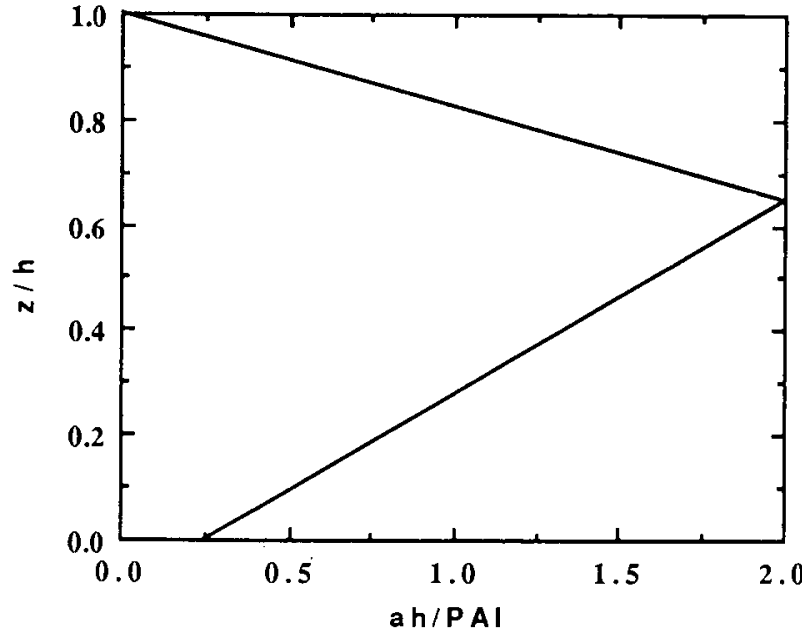

Fig. 1. The plant area distribution, a, i.e. one-sided plant area per volume air $\left(\mathrm{m}^{2} \mathrm{~m}^{-3}\right)$ nondimensionalized with the canopy height, $\mathrm{h}$, and scaled with the plant area index PAI vs the nondimensional height, $\mathrm{z} / \mathrm{h}$. The area under the curve is equal to 1 with regard to the $y$ axis.

The fast-response thermometers were sampled at $5 \mathrm{~Hz}$. All other fast-response instruments were sampled at $10 \mathrm{~Hz}$, while all slow-response instruments were sampled at $1 \mathrm{~Hz}$. The signals were carried to a mobile measurement van, about $100 \mathrm{~m}$ from the instruments. Here, the unconditioned data were dumped on a digital magnetic tape for later analysis. More details about measurement techniques are provided in Jacobs \& Van Boxel (1988a).

\section{Results and discussion}

For two selected days, the most important weather conditions have been portrayed in Fig. 2. July 29 was a windy day with intermittent cloudiness while July 30 was a moderate fine day with less wind and a more regular irradiation pattern. To provide insight into the general canopy characteristics, the course of the 30-minute mean temperature profiles, measured at $0.25 \mathrm{D}$ of the row, have been depicted in Fig. 3 for both selected days. Here, the heights have been nondimensionalized with the height of the canopy $(\mathrm{h}=1.7 \mathrm{~m})$. 

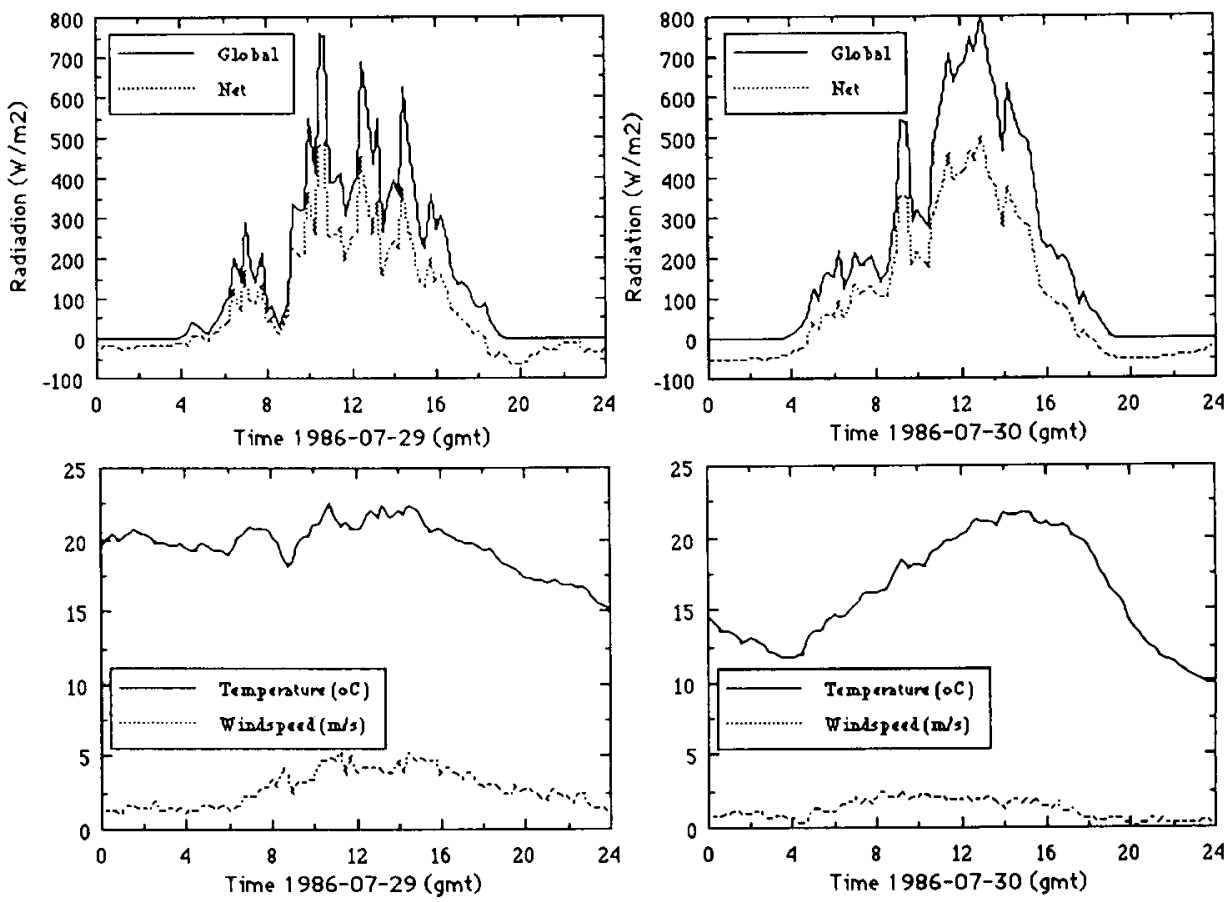

Fig. 2. General meteorological characteristics during two selected days. Temperature and wind speed are measured about $2 \mathrm{~m}$ above crop height.

From Fig. 3 it can be inferred that during daytime, as expected, the maximum air temperature occurs near the top of the canopy at a height of about $\mathrm{z} / \mathrm{h}=0.6$. It is interesting to note that the height $\mathrm{z} / \mathrm{h}=0.6$ coincides (see Fig. 1) with the maximum of the plant area distribution. Moreover during daytime, a second local maximum occurs in the lower region $(\mathrm{z} / \mathrm{h} \sim 0.1)$ of the canopy. During night time, however, two clear maxima can be distinguished one at the floor of the canopy and one at the top of the canopy. The first one is caused by the upward soil heat flux and the second one is an inversion caused by radiative cooling near the top of the canopy.

It is also observed that the maximum temperature difference within the profile ranges between $0-2{ }^{\circ} \mathrm{C}$ during daytime and $0-4{ }^{\circ} \mathrm{C}$ during night time. This result differs somewhat from the results of Graser et al. (1987) for their narrow-row canopy ( $0.76 \mathrm{~m}$ spacing). They found for their central mean profiles differences around $6^{\circ} \mathrm{C}$ during daytime and $3{ }^{\circ} \mathrm{C}$ during night time. A possible reason is the difference in daytime irradiation regime. In a moderate climate, the diffusive incoming radiation often dominates, which causes a reduction of extremes (Jacobs \& Van Pul, 1990).

In the upper frames of Fig. 4, the daytime profiles of the dimensionless temperature difference, $\left.(\mathrm{T}(\mathrm{z})-\mathrm{T}) \mathrm{d}+\mathrm{z}_{\mathrm{o}}\right)$ )/ $\mathrm{T}^{*}$, have been plotted. Here, the daytime temperature profiles are nondimensionalized with the scaling temperature, $\mathrm{T}^{*}$. The procedure has been executed in the same way as it follows from general theory for the above 

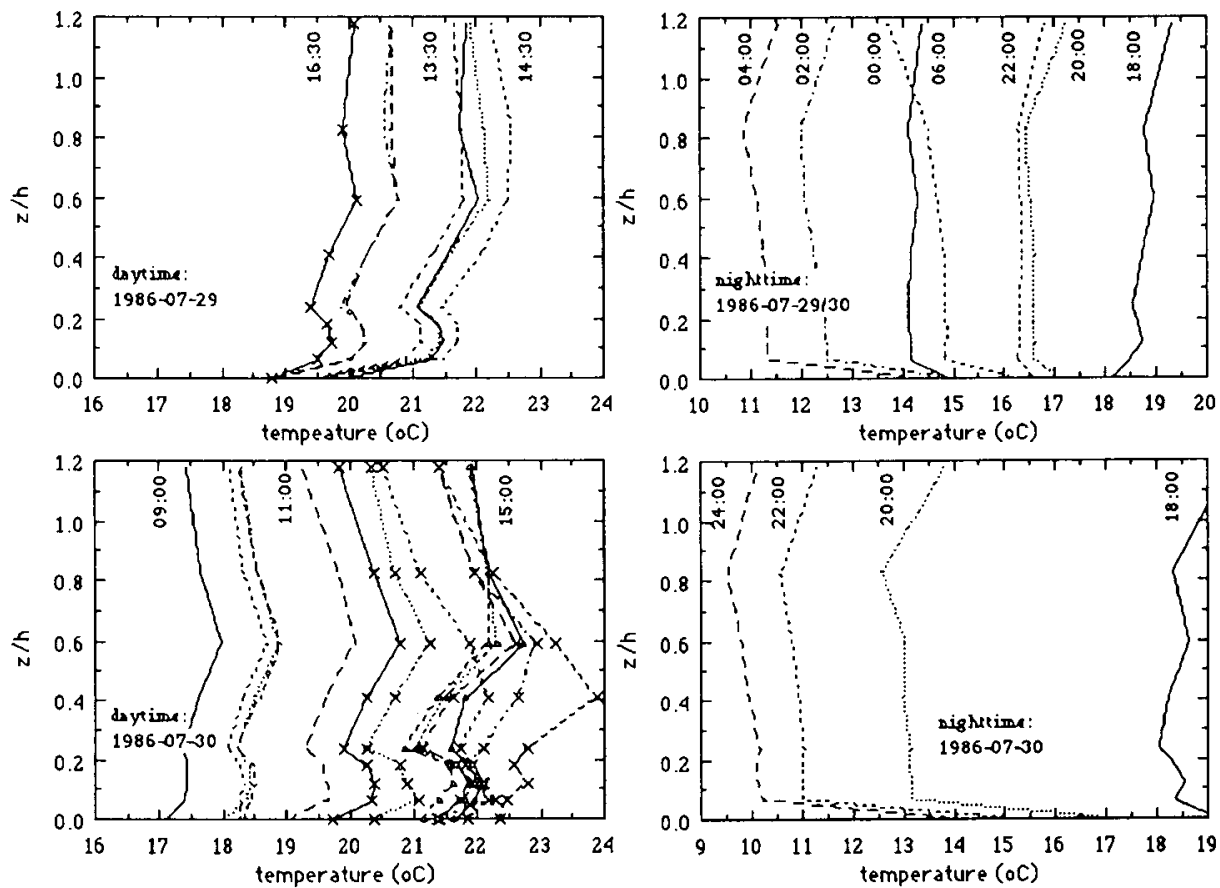

Fig. 3. The course of the within-canopy air temperature profile during a windy and cloudy day (29 July) and a moderate fine day ( 30 July) in 1986. For some profiles the times have been indicated at the left-hand side of the profiles. In the right-hand side top frame the late hours are for June 29 and the early hours for June 30 .

canopy state (see eq. (1)). In the present study, the displacement height and roughness length have been assumed to be (Jacobs \& Van Boxel, 1988a,b) $d=0.75 \mathrm{~h}$ and $\mathrm{z}_{\mathrm{o}}=0.25$ (h-d), respectively. This means that the height, $\mathrm{d}+\mathrm{z}_{\mathrm{o}}$, agrees well with an inside canopy level of $\mathrm{z}=1.4 \mathrm{~m}$. That is why the mean temperature at this level has been assumed to be the reference temperature $T\left(d+z_{0}\right)$. Here, the highest profile density can be taken for guidance in evaluating the averaged dimensionless temperature profile. It can be inferred from this result that the dimensionless profiles for a particular day are similar in shape under above-canopy unstable stratification and scale well for a particular day with the above-canopy scaling temperature, $T^{*}$.

From the daytime results of Fig. 4, we observe clearly that the shape of the dimensionless temperature profiles differ considerably for different days. Probably there are other processes not included in the present temperature scale, $T^{*}$, which are responsible for these effects. Two important differences between both analyzed days are the irradiation regime and the wind regime (see Fig. 2). It is therefore reasonable to assume that different irradiation regimes (i.e. differences in ratio of direct and diffusive radiation) and wind will affect the shape of the temperature profiles. It also must lead to the conclusion that there is no unique simple temperature scale for daytime situations that provides a universal within-canopy temperature profile. 

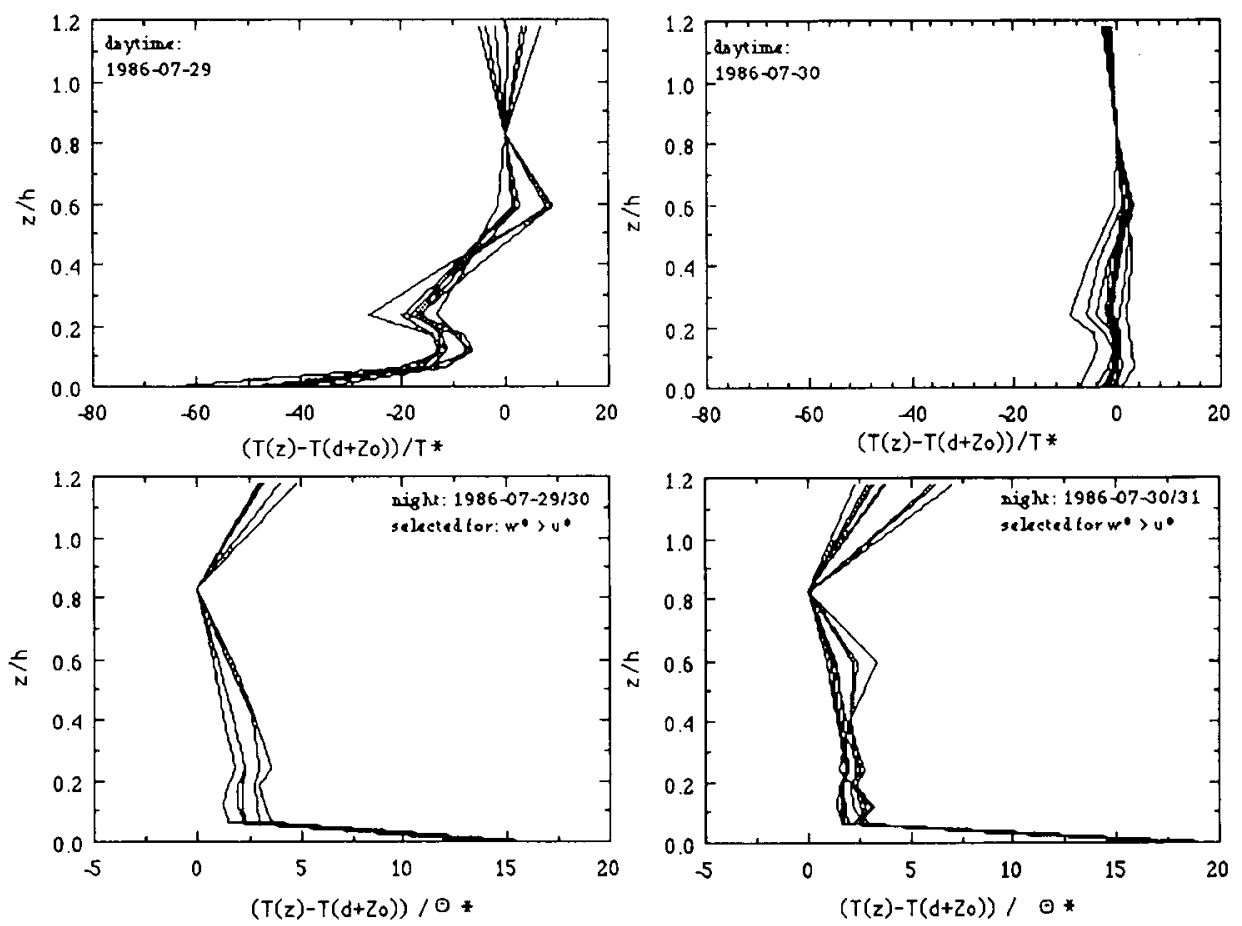

Fig. 4. The 30-minute average within-canopy air temperature measured at $0.25 \mathrm{D}$ ( $\mathrm{D}$ is row distance). The top shows daytime results of 29 and 30 July in 1986, nondimensionalized with the scaling temperature $T^{*}$; the bottom shows night time results under low wind speed conditions nondimensionalized with the free convective temperature scale $\Theta^{*}$.

In the lower part of Fig. 4, the results for July 1986 have been plotted for calm night time situations when the above canopy stratification was stable $(5 \mathrm{~m}>\mathrm{L}>0 \mathrm{~m})$ and the wind speed was low $\left(\mathrm{U}(10 \mathrm{~m})<2 \mathrm{~ms}^{-1}\right)$. Here, the profiles of the temperature difference, $T(z)-T\left(d+z_{o}\right)$, have been nondimensionalized with the free convection temperature scale $\Theta *$. It can be inferred from this result that the dimensionless profiles for both nights are similar in shape under above-canopy stable strafitication and scale well with the within-canopy free convection temperature scale, $\Theta *$.

In Fig. 5, the horizontal mean temperature distribution with regard to the spatially averaged temperature, $\langle\mathrm{T}\rangle$, has been plotted for two levels $(\mathrm{z} / \mathrm{h}=0.4,0.2)$. From this result it can be inferred that for both levels the maximum temperature lies more or less in the center of the row while the minimum lies near the stems of the plants. Moreover, this result indicates that for both levels, except for some exceptions, a mean maximum temperature difference can occur somewhat between $0.2-0.5^{\circ} \mathrm{C}$, which is rather moderate. This result agrees roughly with that found earlier by Graser et al. (1987) for their narrow-row canopy. They also found the maximum temperature in the center of the row but their spatial variation of about $1{ }^{\circ} \mathrm{C}$ was larger than that reported here. 

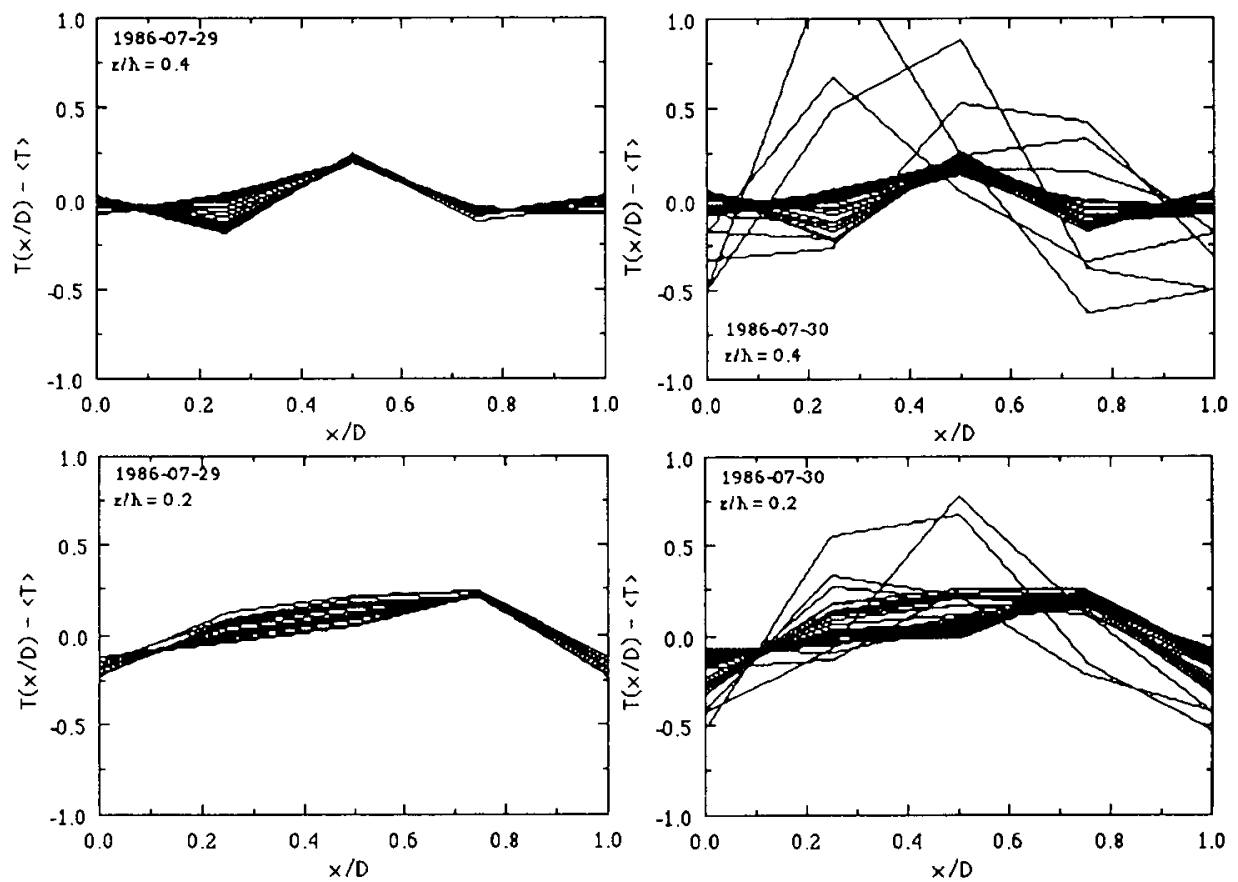

Fig. 5. The deviation of the within-canopy mean temperature $\left({ }^{\circ} \mathrm{C}\right)$ with respect to the spatially averaged values at two levels. Top: $\mathrm{z} / \mathrm{h}=0.4$, bottom: $\mathrm{z} / \mathrm{h}=0.2$.

The few extreme exceptions from Fig. 5 were found on the sunny day only (July $30,1986)$ and occurred around noon. In Fig. 6 , these extremes have been portrayed in more detail. From this result a time course in the pattern of the horizontal temperature distribution can be clearly observed. This pattern is a result of the direct irradiation regime in conjunction with the orientation of the rows (NNE-SWW). In Fig. $6, x / D=1$ aligns with the western side of the row while $x / D=0$ aligns with the eastern side. The influence of midday solar irradiance diminishes with depth inside the canopy.

In Fig. 7, the time course of the variance of the horizontal spatial temperature variability, $\sigma_{\mathrm{T}}$, has been depicted for both selected days by plotting the spatial temperature variance. From this result three characteristics can be observed. First, the nighttime variance of the horizontal temperature is extremely low and lies around $0.1^{\circ} \mathrm{C}$. Second, the daytime variance is higher, and, depending on the irradiation regime and wind speed, can vary between $0.1{ }^{\circ} \mathrm{C}$ and $0.25^{\circ} \mathrm{C}$ for non-midday hours. The more dominant the diffusive irradiation and the higher the wind speed, the lower the spatial variance since cloudiness and wind speed reduce temperature differences both above and inside the canopy. Third, around midday hours when the direct beam dominates, a sudden increase of about $1{ }^{\circ} \mathrm{C}$ in the spatial variance is observed. At this time, the radiation load for the sunlit leaves is maximal and hence the absorption differences between sunlit and shaded leaves is most extreme. Moreover, in the 

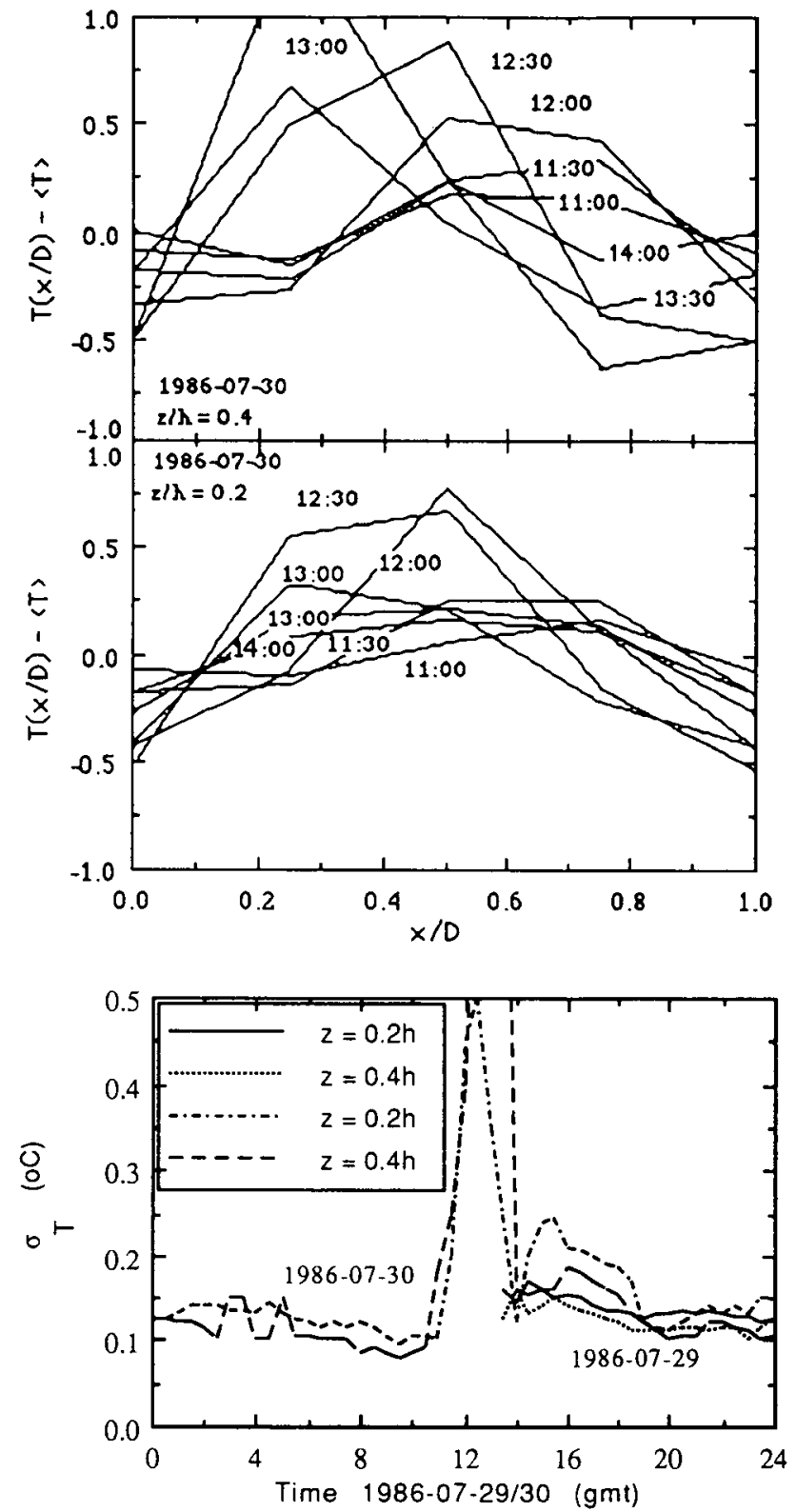

Fig. 6. The deviation of the within-canopy mean temperature $\left({ }^{\circ} \mathrm{C}\right)$ with regard to the spatially averaged values at two levels around noon. Top: $\mathrm{z} / \mathrm{h}=$ 0.4 , bottom: $\mathrm{z} / \mathrm{h}=0.2$.

Fig. 7. The course of the spatial horizontal temperature variability at two levels $(\mathrm{z} / \mathrm{h}=0.2$, 0.4 ) during 29 and 30 July 1986.

present experiment the incoming direct irradiation is clearly parallel to the canopy rows, and consequently, can penetrate deeply into the canopy.

The structure of a row canopy can be open or closed. This difference in row characteristic lead to a quite different behavior of the within-canopy temperature as well as the wind speed. In the middle of the row of a closed canopy, somewhat below 
the canopy height, the highest concentration of foliage occurs. There, the highest absorption of shortwave radiation occurs resulting in a maximum in the horizontal temperature distribution. Indeed this behavior is clearly shown by the present results and agrees with that found by Graser et al. (1987) for their narrow-row sorghum field. However, for a much wider canopy, there is open space between the rows. Within this space no interception and absorption of shortwave radiation occurs. Consequently, a minimum in the horizontal temperature distribution, the cold midcavity region, must be expected. This effect is not shown by the present results but is clearly shown by those of Graser et al. (1987) for their wide-row canopy $(\mathrm{D}=1.5 \mathrm{~m})$.

As already seen in Fig. 5, a maximum temperature difference of around $0.35{ }^{\circ} \mathrm{C}$ can occur within a row. To obtain some insight into temperature difference at various locations along a row and across rows, the temperature differences at a single height $(\mathrm{z} / \mathrm{h}=0.4)$ with respect to the spatial mean have been plotted in Fig. 8. Typical departures from the spatially averaged temperature are also of the order of $0.35^{\circ} \mathrm{C}$.

Between points within the canopy, including within a row itself, microscale advection of sensible heat occurs. A rough estimate of this horizontal transport can be made with the present data. If there exists a horizontal mean temperature difference, the amount of advective heat transport, $\mathrm{H}_{\mathrm{adv}}$, can be written as:

$$
H_{a d v}=p c_{p} \int_{o}^{h} v_{i} \frac{d T}{d x_{i}} d z
$$

where, $v_{i}\left(d T / d x_{i}\right)$ is the dot-product of the horizontal velocity and the horizontal temperature gradient. During the experiments it appeared that a good estimate for the mean horizontal wind speed was about $0.10 \mathrm{~ms}^{-1}$ (Jacobs et al., 1991). This means that with eq. (3) a maximum within-row and across-row advection is estimated to be

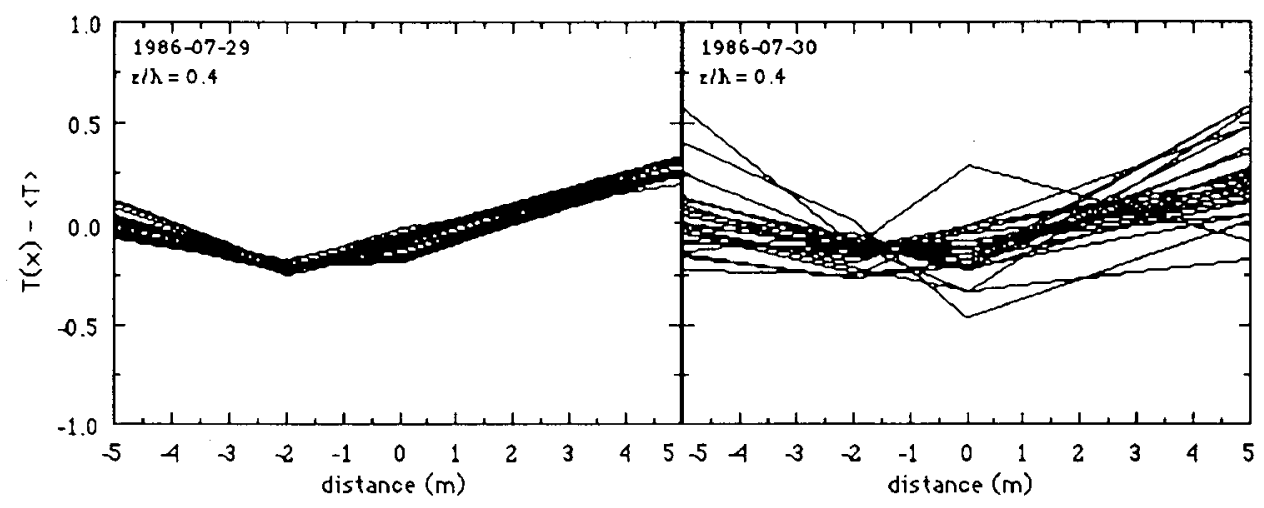

Fig. 8. The relative within-canopy mean temperature for various locations with regard to their spatially averaged value, measured at $\mathrm{z} / \mathrm{h}=0.4$ and $0.25 \mathrm{D}(\mathrm{D}=$ row distance). Negative signs mean distances along the row and positive signs mean distances across the row. 


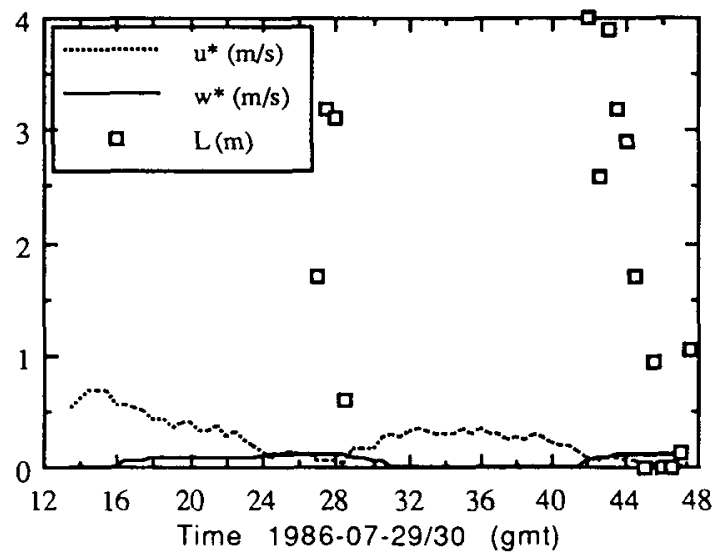

Fig. 9. The course of the friction velocity, $\mathrm{u}^{*}$, and free convection velocity scale, $w^{*}$, during both selected days. The stability length scale, $\mathrm{L}$, has been plotted only when the free convection velocity scale dominates.

$45 \mathrm{Wm}^{-2}$ and $7 \mathrm{Wm}^{-2}$, respectively. An within-row advection of sensible heat of around $50 \mathrm{Wm}^{-2}$ is mentioned in literature for a homogeneous canopy. For example, Johnson et al. (1976) found about $40 \mathrm{Wm}^{-2}$.

Horizontal mean temperature differences of $0.35^{\circ} \mathrm{C}$ are small and it can be assumed that these differences commonly occur in practice in a dense canopy. Possible causes are, for example, slight irregularities in plant development, differences in mutual shading effects and soil irregularities. This means that the previously mentioned within-row advective heat fluxes of about $40 \mathrm{Wm}^{-2}$ are more normal than exceptional.

During night time, the above-crop wind speed drops with a resulting decrease in the friction velocity, $u^{*}$, while the within-canopy free convection velocity, $w^{*}$, will be of increasing importance. Jacobs et al. (1992) found that within the above-canopy thermal stability range of $0 \mathrm{~m}<\mathrm{L}<5 \mathrm{~m}$, the within-canopy wind speed profile scales excellently with the free convective velocity scale. From Fig. 9, it is shown that this situation agrees with periods when the convective velocity scale, $w^{*}$, exceeds the friction velocity scale, $\mathbf{u}^{*}$.

It is of interest to find out if, when the free convective scale, $w^{*}$, dominates, the within-canopy state agrees with the often used criteria based on the Grashof and Reynolds numbers in technical problems (Monteith \& Unsworth, 1990):

Free convection: $\mathrm{Gr}>16 \mathrm{Re}^{2}$

Forced convection: $\mathrm{Gr}<0.1 \mathrm{Re}^{2}$

Mixed convection: $16 \mathrm{Re}^{2}<\mathrm{Gr}<0.1 \mathrm{Re}^{2}$.

Here, the Grashof number is $\mathrm{Gr}=\mathrm{a} g \Delta \mathrm{T} \mathrm{h} *^{3} / \nu^{2}$ ( $\mathrm{g}$ is gravity, $\mathrm{a}=1 / \mathrm{T}$ is the thermal expansion coefficient, $h^{*}$ is characteristics length scale and $v$ is kinematic viscosity) and the Reynolds number is $\operatorname{Re}=u^{*} h^{*} / \nu$. The length scale $h^{*}=d+z_{o}$ was chosen. In Fig. 10 these criteria as well as the results for the selected nights of 29 and 30 July have been plotted. From these results it can be observed that, when the convective velocity scale exceeds the friction velocity the above criteria (4) indicate a free convection state within the canopy. Moreover, it can be concluded that during all other nighttime situations the criterion of eqs. (4) indicate a mixed convection state. 

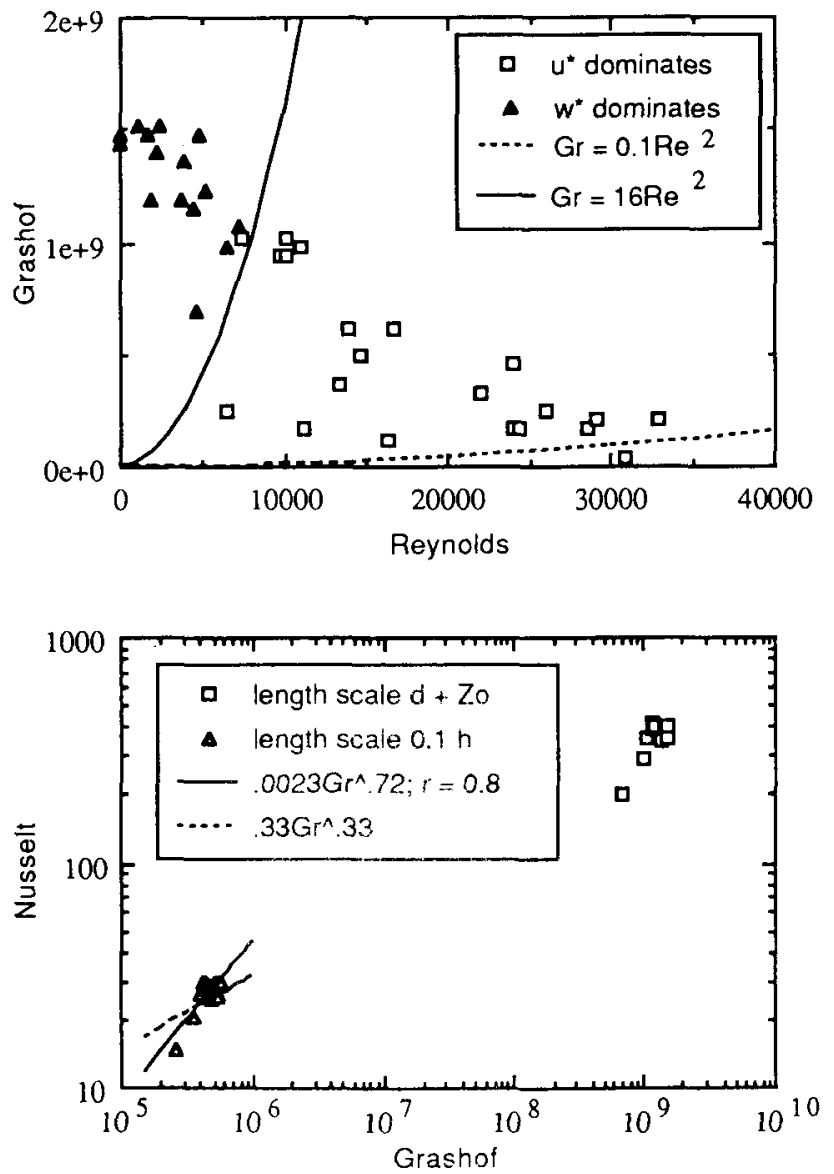

Fig. 10. The Grashof number $\left(\mathrm{Gr}=\mathrm{ag} \mathrm{h}{ }^{* 3} \Delta / v^{2}\right.$, where $\mathrm{h}^{*}=$ $\mathrm{d}+\mathrm{z}_{\mathrm{o}}$ ) vs. the Reynolds number $\left(\operatorname{Re}=u^{*} h^{*} / v\right)$. For nighttime observations, the free convection criterion, $\mathrm{Gr}=16 \mathrm{Re}$ and the forced convection criterion, $\mathrm{Gr}=0.1 \mathrm{Re}^{2}$ ) have been indicated.
Fig. 11. The Nusselt number $\left(N u=q_{s} h^{*} /(\lambda \Delta T)\right)$ vs Grashof number $\left(\mathrm{Gr}=\right.$ ag $\mathrm{h}^{* 3} \Delta \mathrm{T} / \nu^{2}$ where $h^{*}$ is either $0 / \mathrm{h}$ or $\mathrm{d}+\mathrm{z}_{\mathrm{o}}$ ). A linear best fit relation as well as a relation with a fixed exponent of 0.33 have been indicated.

It must be noted, however, that under nighttime strong wind conditions the forced convection state can be reached easily.

In Fig. 11 the Nusselt number, $\left.N u=q_{s} h^{*} / \lambda \Delta T\right)\left(q_{s}\right.$ is the soil heat flux, $\lambda$ is molecular conductivity of heat in still air) versus the Grashof number has been plotted. From this result it can be seen that the data points (open squares) lie far from the regions $\left(\mathrm{Nu} \sim O\left(10^{1}\right)\right.$ and $\mathrm{Gr} \sim O\left(10^{5}\right)$, where $\bigcirc$ means order of magnitude) often mentioned in literature (e.g. Jakob, 1950). In engineering problems, however, a different length scale is suggested, namely, the depth across which the actual temperature gradient occurs. From Fig. 3 we infer that this scale is about $10 \%$ of the canopy height. For this reason, the data are replotted in Fig. 11 using the Grashof and Nusselt numbers with length scale $\mathrm{h}^{*}=0.1 \mathrm{~h}$, together with the best fit line $(\mathrm{Nu}=$ $0.023 \mathrm{Gr}^{0.72}$ ) and the relation $\mathrm{Nu}=0.33 \mathrm{Gr}^{0.33}$. In the latter relation, the exponent 0.33 represents a numerical value which often emerges as best fit in engineering problems. The coefficient 0.33 was found as the best fit through the mass of points. We 
can conclude that the newly obtained results agree reasonable well with those found in literature.

\section{Conclusions}

From the foregoing results the following main conclusions can be drawn:

1) In a moderate climate the maximum difference within the mean temperature profile of a dense homogeneous row canopy lies somewhere around $2{ }^{\circ} \mathrm{C}$ during daytime and around $4{ }^{\circ} \mathrm{C}$ during nighttime.

2) The horizontal variability of the mean air temperature in a row crop is moderate and restricted to about $0.35^{\circ} \mathrm{C}$ of its spatial mean value. Here, the maximum value occurs in the center between the rows while the minimum value occurs near the stems. The same pattern is observed in the upper as well as the lower canopy region. Exceptions occur around midday when direct radiation dominates. Then, a variability of. $1{ }^{\circ} \mathrm{C}$ or more can be observed.

3) The present results for the horizontal variability roughly agree with those found by Graser et al. (1987) for their narrow-row canopy.

4) During unstable stratification states (daytime) the within-canopy mean temperature profiles can be scaled well by the above-canopy scaling temperature, $T^{*}$, for a particular irradiation and wind speed regime. This means that under these conditions, above-canopy and within-canopy flow is strongly coupled.

5) During nights with less wind, a decoupling between the above-canopy and within-canopy flow occurs. Here, the within-canopy free convective flow is forced by the soil heat flux at the floor of the canopy. Under these conditions, the within-canopy temperature profiles scale well with the free convective within-canopy temperature scale, $\Theta *$.

6) Inter-row and along-row advection are of minor significance in a dense homogeneous canopy. In practice this suggests that within a dense homogeneous canopy the transport of heat can be considered vertically.

7) The criteria of eqs. (4) apply well for the within-canopy heat transport process to distinguish the convection type. The boundary between the free convection and mixed convection states can also be found by comparing the above-canopy friction velocity and the within-canopy free convective velocity scale.

8) In modeling transport processes within a plant canopy, the present results suggest that during daytime hours nearly always mixed convection dominates while during nocturnal hours, when $\mathrm{w}^{*}>\mathrm{u}^{*}$, the free convection dominates.

\section{Acknowledgements}

The authors' grateful thanks are offered to the Institute for Land and Water Management (ICW) for permission to use facilities of the pilotfarm Sinderhoeve. J.H. van Boxel was supported financially by the Working Group on Meteorology and Physical Oceanography (MFO) from the Netherlands Organization for Advancement of Pure Physics (ZWO). 


\section{A.F.G. JACOBS, J.H. VAN BOXEL AND R.H. SHAW}

\section{References}

Arya, S.P., 1988. Introduction to Micrometeorology. Academic Press, San Diego, $307 \mathrm{pp}$.

Finnigan, J.J. \& M.R. Raupach, 1987. Transfer processes in plant canopies in relation to stomatal characteristics. In: E. Zeiger (ed.), Stomatal Function, p. 385-429. Stanford University Press.

Garratt, J.R. \& M. Segal, 1988. On the contribution to dew formation. Boundary-Layer Meteorology 45: 209-236.

Graser, E.A., S.B. Verma \& N.J. Rosenberg, 1987. Within-canopy temperature patterns of sorghum at two row spacings. Agricultural and Forest Meteorology 41: 187-205.

Jacobs, A.F.G. \& J.H. van Boxel, 1988a. Changes of the displacement height and roughness length of maize during a growing season. Agricultural and Forest Meteorology 42: 53-62.

Jacobs, A.F.g. \& J.H. van Boxel, 1988b. Computational parameter estimation for a maize crop. Boundary-Layer Meteorology 42: 265-279.

Jacobs, A.F.G. \& W.A.J. van Pul, 1990. Seasonal changes in the albedo of a maize crop during two seasons. Agricultural and Forest Meteorology 49: 351-360.

Jacobs, A.F.G, W.A.J. van Pul \& A. van Dijken, 1991. Similarity dew profiles within a corn canopy. Journal of Applied Meteorology 29: 1300-1306.

Jacobs, A.F.G., J.H. van Boxel \& R.H. Shaw, 1992. The dependence of canopy layer turbulence on within-canopy thermal stratification. Agricultural and Forest Meteorology 58: 247-256.

Jakob, M., 1950. Heat Transfer. John Wiley \& Sons, New York, 758 pp.

Johnson, C.E., P.V. Biscoe, J.A. Clark \& E.J. Littleton, 1976. Turbulent transport in a barley canopy. Agricultural Meteorology 16: 17-35.

Monteith, J.L. \& M.H. Unsworth, 1990. Principles of environmental physics. Edward Arnold, London, $291 \mathrm{pp}$.

Mulheam, P.J. \& J.J. Finnigan, 1978. Turbulent flow over a very rough, random surface. Boundary-Layer Meteorology 15: 109-132-

Raupach, M.R. 1988. Canopy Transport Processes. In: W.L. Steffen \& O.T. Denmead (Eds), Flow and Transport in the Natural Environment, p. 95-127. Springer Verlag, New York.

Shaw, R.H., G. Den Hartog, K.M. King \& G.W. Thurtell, 1974. Measurements of mean wind flow and three dimensional turbulence intensity within a mature corn canopy. Agricultural Meteorology 13: 419-425.

Stigter, C.J., J. Birnie \& P. Jansen, 1976. Multi-point temperature measuring equipment for crop environment, with some results on horizontal homogeneity in a maize crop. Netherlands Journal of Agricultural Science 24: 223-237.

Tennekens, H. \& J.L. Lumley, 1972. A First Course in Turbulence. The MIT Press, Cambridge, $300 \mathrm{pp}$.

Van Asselt, C.J., A.F.G. Jacobs, J.H. van Boxel \& A.E. Jansen, 1991. A rigid fast-response thermometer for atmospheric research. Measurement Science \& Technology 2: 26-31.

Weiss, A.A. \& J.M. Norman, 1987. Comparison of field measurements and numerical simulations of leaf wetness duration in a dry bean canopy. Proceedings 18th Conference on Agricultural and Forest Meteorology. A.M.S. Sep, 15-18, p. 52-53.

Zhang, Y. \& T.J. Gillespie, 1990. Estimating maximum droplet wetness duration on crops from nearby weather station data. Agricultural and Forest Meteorology 51: 145-158. 